\title{
Personajes ficcionales para creación literaria ${ }^{1}$
}

\author{
John Edward González González²
}

Universidad Santo Tomás, Bogotá, Colombia

johngonzalez@ustadistancia.edu.co

1 Artículo de investigación científica desarrollada con el apoyo de la U. Santo Tomás en el año2014.

2 *Estudiante de la Licenciatura en Educación Básica énfasis en Humanidades y Lengua Castellana. 
Tema Libre

\title{
Personajes ficcionales para creación literaria
}

\section{Resumen}

Este proyecto de investigación identifica estrategias pedagógicas a partir de personajes ficcionales que les guste a niñas y niños de 7 a 9 años para motivar sus habilidades en creación literaria; se propone llevar a los estudiantes en un proceso de escritura creativa tomando como mediación las TIC, con el fin de aprovechar personajes, historias y temas para sus procesos de originalidad. Se desarrollan diversas actividades lúdicas para que los estudiantes construyan sus propios textos, orales, escritos y pictóricos, donde niñas y niños expresen sus pensamientos y sentimientos desde una óptica de autodescubrimiento de sus capacidades. Además, para que puedan reconocer los valores morales y éticos y se empiecen a preparar en la resolución de problemas desde los retos que se les pone para ubicar contextos y narrar historias creativamente.

Palabras clave: Creación literaria, escritura, infantil, mediación, TIC.

\section{Fictional characters for literary creation}

\begin{abstract}
This project identifies pedagogical strategies based on fictional characters that children between the ages of 7 and 9 like, in order to develop their abilities of literary creation; it proposes to bring the children on a process of creative writing using ICT as an educational mediation; the last with the intention of taking advantage of characters, stories and topics to encourage their own originality process. Diverse ludic activities are developed for the children to build their own oral, written or pictorial texts, on which they express their thoughts and feelings from the perspective of self discovering of their own capabilities; also, the children can recognize the moral and ethical values, and they begin to prepare for the resolution of problems from the challenges proposed to them to locate contexts and creatively narrate stories.
\end{abstract}

Keywords: literary creation, writing, childhood, ICT mediation.

\section{Personagens ficcionais para criação literária}

\section{Resumo}

Este projeto de investigação identifica estratégias pedagógicas, a partir de personagens ficcionais, que agradem às meninas e aos meninos de 7 a 9 anos, para motivar suas habilidades em criação literária; propõe-se levar aos estudantes em um processo de escritura criativa, tomando como mediação as TIC, com o fim de aproveitar personagens, histórias e temas para seus processos de originalidade. Portanto, desenvolvem-se diversas atividades lúdicas para que eles construam seus próprios textos orais, escritos e pictóricos, onde meninas e meninos expressem seus pensamentos e sentimentos desde uma óptica de autodescobrimento de suas capacidades, e possam reconhecer os valores morais e éticos, e comecem a se preparar para a resolução de problemas, desde os retos que lhes propõem, para localizarem contextos e narrarem histórias criativamente.

Palavras-chave: criação literária, escritura, infantil, mediação TIC. 


\section{Introducción}

Es muy frecuente escuchar que la televisión -y los medios audiovisuales en general_ " "embrutecen" a las personas, les hacen perder habilidades cognitivas o que, definitivamente, no tienen nada bueno qué enseñar. Aunque es dura esa afirmación, sí se puede hacer algo para sacarle provecho a estos medios de difusión; en particular, sirven para motivar en niñas y niños procesos creativos y originales, que les permitan modelar en sus mentes sistemas de comunicación efectivos a partir de un proceso de creatividad literaria y artística.

Enseñar a escribir no es un tema exclusivo de motricidad o habilidad de los músculos, está más relacionado con el lenguaje interior porque se necesita un proceso mental complejo para que, a partir de una pequeña idea y las ganas de contarla, se pueda armar un contexto planeado, ejercitar — ahora sí - el sistema motriz para llenar un papel con trazos bien formados, corregir y editar lo plasmado. Esto funciona de manera similar para escribir una lista de mercado o una novela de mil páginas.

Hay que comprender que cualquier actividad humana que se difunda por un medio de comunicación electromagnético tiene de fondo un contenido que se puede leer, ese proceso lector de imágenes visuales y sonoras debe ser enseñado y motivado en las personas para que aprovechen realmente un potencial de datos que los forme integralmente, sobre todo en valores y virtudes.

A los niños les gusta el cine, la televisión, los videojuegos y las aplicaciones de internet porque ahí están leyendo la información que se les brinda; las imágenes y secuencias llenan sus sentidos de datos que se aglomeran en su mente, y es deber de maestros y padres darles buenas bases para dar sentido a esos textos. Es necesario que analicen (dividan) y sinteticen (reúnan) los bloques de datos, además, que a partir de ahí se formen un significado inicial, y luego puedan hacer un proceso relacional (orden, series, agrupamientos) e inferencial (comprensión compleja, anticipaciones, cierres) de todo lo que han entendido. Es igual a leer un libro.

En el ámbito académico se pueden aprovechar las TIC como mediadoras en los procesos de enseñanza y de aprendizaje; es decir, para que sean un agente del cual maestros y estudiantes tomen temas, personajes y datos, para apoyar su formación personal, adquirir conocimiento y utilizar lo que saben de una manera práctica, entender y solucionar los inconvenientes y problemas, innovar e inventar; en fin, para ser útiles a sus semejantes.

En particular, se espera que niñas y niños tengan un apoyo de sus personajes y 
programas favoritos, de los videojuegos, de los contenidos audiovisuales y lúdicos que existen en internet, para motivar sus procesos creativos literarios y artísticos; que aprovechen las TIC para ganar en originalidad y en desarrollo de su lenguaje interior, fuente de su expresión comunicativa, y con ello desarrollen mejor sus procesos axiológicos y de comportamiento en sociedad.

\section{Antecedentes}

La creación literaria en los niños del primer ciclo de primaria ha sido escasa, parece que están muy pequeños para tener un lenguaje lo suficientemente amplio y rico para expresar sus sentimientos, deseos y conceptos en una obra artística; además, se puede pensar que su conjunto de experiencias de vida son pocas, por lo cual no se llevarían a cabo procesos adecuados para la producción creativa.

La mayoría de las didácticas tradicionales utilizadas en las escuelas del país tienen como premisa métodos sintéticos de aprendizaje de la lectura y la escritura, empezando por el conocimiento de las letras, sus sonidos, las sílabas, hasta formar palabras; pero toda su vida, niños y niñas han estado en contacto con ideas totales, con enunciados completos, y hasta discursos enteros; esta sencillez sintética a veces perjudica todo el proceso de comunicación que han tenido desde sus primeros días de vida.

Además, para enseñar a leer y escribir se ha dejado de lado la oralidad del estudiante, sus procesos pictóricos y artísticos, sus capacidades motrices corporales, y las relaciones de su cuerpo con la música, lo cual genera un proceso autómata de decodificación de los signos escritos, y no se aprovecha toda la capacidad de significación que han ganado durante su etapa preescolar; esto coarta los procesos creativos posteriores en la vida académica.

Se hace notar que el acompañamiento de la familia y el buen ejemplo que reciban niñas y niños de los adultos, respecto a hábitos de lectura y escritura, producen en ellos una percepción más profunda de estos procesos, con lo cual se apropian desde pequeños de ciertas hipótesis y saberes sobre leer y escribir que les permite sumergirse más tranquilamente en sus actividades escolares, obteniendo mejores resultados en su comprensión general.

En el 2004, el ICBF contrató algunas entidades para realizar estudios que permitieran conocer el estado de la lectura en la primera infancia; a partir de éstos se encuentra que "hay un desfase entre la capacidad de decodificación mecánica y la necesidad de desciframiento vital" (Reyes, 2005, p. 24); y se establece que el vínculo de los adultos en el apoyo lector fomentan en los niños mejores desarrollos de lenguaje verbal y no verbal, y relacionan entonación con signos ortográficos (Reyes, 2005, pp. 25-26). 
En 2010, la Secretaría de Educación Distrital de Bogotá publicó unos Referentes para la Didáctica del Lenguaje; para el primer ciclo de educación, enfatiza en el ingreso de los niños a la cultura escrita, pues, más que tener idea del código se requiere una orientación crítica que permita el acceso a la cultura de la humanidad, y que se pueda pensar sobre el lenguaje, el mundo y sobre ellos mismos (Pérez y Roa, pp. 27-28).

Con estas referencias se ve la problemática de la lectura y la escritura no como un proceso aislado, o al que sólo se puede llegar en diversas etapas del desarrollo cognitivo de los infantes, sino en el que se debe aprovechar las capacidades innatas en la construcción del lenguaje, y solventar necesidades diferentes para la enseñanza de la lectura y escritura a partir del apoyo de padres y maestro. Lo anterior mostrando un horizonte crítico a los niños, que les permita un contacto más íntimo con el mundo que los rodea, con sus pensamientos y sentimientos.

Es necesario que el proceso escritor de los niños y niñas se utilice también para formar competencias en creación literaria; se pretende establecer como prioridad la lúdica y los juegos para generar creatividad expresiva, y que las mediaciones tradicionales, como libros y cuentos, se apoyen con los nuevos lenguajes audiovisuales que nacen de las TIC.

Desde hace unos años con el auge de internet y las nuevas facilidades de acceder a programación televisiva internacional se han venido haciendo propuestas para motivar procesos de lectura separada de los libros. Los hipertextos electrónicos dan un espectro para la adquisición de conocimiento y de entretenimiento desde los primeros años de vida y, además, motivan diversas competencias lectoras en los estudiantes.

Las imágenes ahora prevalecen sobre el texto escrito y esto ha generado "un cierto cambio de modelo cultural (...) que implica ciertas modificaciones en el uso del lenguaje y, sobre todo, en las capacidades de razonamiento" (Cerrillo, 2007, p. 10). Este autor asegura que se construye significados de manera diferente y que los nuevos lenguajes audiovisuales hacen que se genere menos conocimiento.

Entonces se debe explorar una nueva manera de que niñas y niños interactúen con los medios de información a su disposición, para poder aprovechar el tiempo que se invierte viendo televisión, navegando por la red, o utilizando los videojuegos, de forma creativa en las aulas de clase; empezando con los procesos de lectura y el desarrollo de sus expresiones literarias, desde sus gustos por la tecnología, su afición por programas y personajes de televisión e internet, y la lectura de sus libros preferidos. 


\section{Problema de investigación}

Se pueden cerrar brechas en las dificultades de competencias comunicativas que están teniendo los niños que estudian sus primeros ciclos escolares, la clave es encontrar una manera de integrar en el aula nuevas estrategias para enseñar a leer, escribir, y a crear historias, usando como mediaciones las TIC y, a su vez, reforzando la oralidad, las formas expresivas a través del arte, las manualidades y la comunicación no verbal.

Como medio integrador se proponen los personajes ficcionales, vistos como aquellos que habitando un mundo irreal de la literatura, televisión, videojuegos o internet, son capaces de establecerse en el gusto de los niños para servir en su interacción con el mundo real, creando relaciones y acciones que cada infante puede llevar a cabo a través de la historia en la que nació el personaje, sus aventuras y en la realidad que niñas y niños tienen en su entorno. De aquí surge la pregunta de investigación: ¿Cómo utilizar los personajes ficcionales para motivar la creación literaria en los niños?

\section{Objetivos}

Como objetivo general se propone: Identificar estrategias pedagógicas con personajes ficcionales que permitan el desarrollo de procesos escriturales y de creación literaria en niños de grado $2^{\circ}$.

Los objetivos específicos son: 1) Experimentar los personajes ficcionales como apoyo para la expresión oral, escrita y artística, utilizando como mediación las TIC. 2) Demostrar que las estrategias son aptas para el desarrollo de la creatividad literaria.

\section{Marco teórico}

Los ejes principales a tratar son: creatividad como medio para romper paradigmas; las mediaciones con TIC para abrir nuevos caminos; y tercero, estrategias pedagógicas a partir de la literatura y la lúdica.

Primero, el campo de la creatividad artística de los niños tiene como resultados previsibles la construcción de estructuras mentales: apertura en relaciones intra e interpersonales, capacidad de discernir sobre lo verdadero y la fantasía; además, se encuentra el factor de preparar a los niños para la resolución de problemas: personales, académicos, del entorno y de su comunidad. Asimismo, lo creativo como base para reforzar la autoestima y la integralidad de su educación; también lo ancestral como fuente de nuevas historias. 
Para Rodari (1983), “"Creatividad» es sinónimo de «pensamiento disidente», es decir de «rompimiento de esquemas». «Creativa» es la mente que trabaja continuamente, siempre dispuesta a hacer preguntas" (p. 150); esta capacidad de admiración busca la pregunta como medio de comunicación y cuando se halla la respuesta también ésta produce más interrogantes.

Los procesos creativos, continúa el autor, nacen de la función liberadora de la palabra en la mente de los infantes; "provoca una serie infinita de reacciones en cadena", y además de actuar en la memoria afecta positivamente la fantasía y el inconsciente; se adentra en el campo de la experiencia y de la ideología de cada niño, además de los ejercicios surrealistas de sus sueños, buscando en lo más profundo para crear historias novedosas (Rodari, 1983, pp. 8-12).

Por su parte, Bustamante y Porras (2010) hablan de la creatividad a partir de tres etapas que han comenzado niños y niñas desde sus años de preescolar con el garabateo, que luego en el colegio bajo una adecuada orientación y estimulación por parte de sus maestros se convierten en dibujos, pinturas y textos escritos, y se ven influenciados positivamente por los cuentos narrados, los hechos cotidianos que viven, y los personajes de la TV (pp. 159-163).

El segundo eje son las mediaciones de las TIC para aportar un tercer agente de donde estudiante y maestro tomen opciones fuertes y precisas para mejorar sus procesos de creatividad literaria, artística, y generar un proceso escritural que se beneficie del análisis crítico de la imagen y lo audiovisual en todas su expresiones. La creación de narrativas, a partir de lo que perciben y entienden de la mediación, genera un nuevo proceso lingüístico aprovechable en su formación. También los enfoques desde el pensamiento interior de los infantes para construir con su imaginación mundos de ficción que se conjugan en lo audiovisual, y en su representación del juego de las historias que más les gustaron.

Se debe diferenciar entre utilizar las TIC como una herramienta para la educación, y como una mediación que permita un proceso de enseñanza y de aprendizaje a partir de los recursos que se tomen de allí. Rovira (2011) encuentra la falta de apoyo de la tecnología en la mediación del aprendizaje en general, no sólo de la creatividad literaria. Se está dejando de lado, dice él, la capacidad de interacción que permite internet y los nuevos recursos comunicativos a los que acceden los niños, y se ocupa gran parte de los recursos únicamente como repositorios de libros o textos infantiles y juveniles (pp. 137-138). 
Dando un aporte desde otro nivel, Dolezel (1999) habla de una "existencia sensible" en las personas; la identificación de personajes de la ficción en las mentes del estudiante pueden influir desde el mundo de la fantasía y transformar significativamente su ser; reflejarán inclusive un estilo literario particular y permitirán el proceso creativo (pp.111-116). Afirma que se pueden crear "lectores modelo" que son capaces de absorber mundos ficcionales, y construir estructuras creativas conjugando varios de esos mundos que ha percibido con sus diferentes lecturas, acceso a los formatos audiovisuales y contacto con su entorno.

Ha sido interesante el punto de vista de Dolezel cuando se refiere a las "estructuras unipersonales y la ficción" en el sentido que los niños crean historias desde su lenguaje interiorizado, tomando como base lo que presentan los medios de comunicación a sus mentes, para crear de ahí ficciones que enriquecen su imaginación, y que luego, con el contacto con amigas y amigos, recrean de una manera intencionada y absorben también los mundos ficcionales de sus interlocutores y compañeros de juego.

Como tercer punto básico del marco teórico, encadenando con el anterior, se observan las estrategias pedagógicas a partir de la literatura y la lúdica. El objetivo de este proyecto de investigación es permitir una formación de niñas y niños hacia la creación de textos orales, escritos, artísticos y de cualquier forma de comunicación humana. El maestro debe servir como guía para motivar la lectura de la literatura, y sembrar en todos los niños un gusto por explorar el mundo a partir de las narraciones y géneros que más le interesen.

Retomando a Rodari (1979), quien hace una reflexión pedagógica sobre la escritura literaria, es posible notar un grado de transversalidad en los cuentos, donde la lógica hace su aparición como operación mental para descubrir ese sentido matemático de "reversibilidad $(A+B=B+A)$ " (pp. 118-120). Los buenos autores enredan sus tramas y es la oportunidad para los niños de descubrir con sus capacidades exploratorias lo oculto y la connotación para desenrollarlas, entenderlas y divertirse.

Igualmente, Rodari hace una crítica a las escuelas al tratar de inculcar un valor por la lectura, pero no por el gusto de leer en los niños. El maestro debe buscar situaciones creativas, ser el promotor de originalidad, no domador de niños, no expendedor de datos; también el docente que se preocupa por la experiencia feliz de los niños hace que se permitan su lado artístico, desarrollen sus valores, cultura y ciencia. Dice Rodari que la fantasía es creadora; la imaginación construye a partir de la realidad; y él aporta unas estrategias y didácticas con el fin de enriquecer a partir de estímulos el ambiente en el que se desenvuelve el niño (pp. 147-150).

Como apoyo pedagógico, la oralidad, actividad a la que han estado habituados durante toda su vida, permite a los niños desarrollar más fácilmente sus procesos comunicativos en toda índole; más si tienen que expresar sus conocimientos a sus 
pares, o si deben dirigir a infantes más pequeños en sus procesos lectores y escritores iniciales. Así afianzan todos sus aprendizajes y pueden realizar distintas cogniciones si encuentran un reto constante para tratar de transmitir sus puntos de vista sobre el conocimiento lector y escrito que poseen.

En muchos casos, según una visión ya muy popular, se toma la televisión y los medios masivos como el causante de baja reflexión y pensamiento de los niños, o como fuente de violencia en algunos sujetos; para Jones (2002) el contacto entre lo narrativo textual y lo audiovisual "les invitan (...) a experimentar sus pensamientos y sentimientos de forma más plena"; la capacidad de acceder a temas multimedia permite "una sensación de autoridad sobre sus emociones y las influencias del mundo" (p. 24) siempre y cuando se les deje expresarse de manera libre y reconstruir sus fantasías en textos orales y escritos, en sus juegos y en su expresión cotidiana.

La acción lúdica a partir de las historias preferidas, inclusive las violentas, explica Jones, es un resultado de la relación emocional que tienen los niños con la fantasía de los autores, es la constancia que esa obras artísticas permean la imaginación, y permiten una representación particular de la realidad. La pistola, formada con la mano, 'mata' al amiguito que disfruta ese disparo, cae y dramatiza su dolor; expresa una realidad que vive, y que puede seguir contando de manera escrita si se le da la oportunidad (Jones, 2002, pp. 68-73).

\section{Metodología}

\section{Técnicas de investigación e instrumentos}

En esta investigación de corte cualitativo se utiliza el método InvestigaciónAcción, donde el maestro investigador planifica, actúa, observa, reflexiona sobre las situaciones en el aula y prepara apoyos y soluciones a las dificultades de enseñanza o de aprendizaje que vayan apareciendo en el transcurso del proyecto de investigación. Rodríguez (1999) afirma que "en las escuelas se analiza las acciones humanas y las situaciones sociales experimentadas por los profesores", intentando explicar lo que sucede desde el punto de vista de los estudiantes (p. 53).

\section{Población y muestra}

La población es niñas y niños de $2^{\circ}$ grado del Colegio Anexo San Francisco de Asís de la localidad de Usaquén, en Bogotá. Sus edades oscilan entre 7 y 9 años, con un proceso lector y escritor en distintos niveles y competencias comunicativas. La muestra son 27 niñas y niños, distribuidos 13 y 14 personitas respectivamente. Todos los sujetos son de las cercanías del colegio, y pertenecen a nivel socioeconómico bajo, con lo cual conforman un conjunto homogéneo, que tienen un comportamiento similar 
ante las situaciones del aula, y en las actividades académicas y extracurriculares en las que participan activamente.

\section{Sistematización de la información}

Respecto al tratamiento y análisis de los datos, los productos realizados por los estudiantes - textos literarios escritos - son expuestos a procesos de reducción, separándolos en unidades temáticas que conformen estructuras discursivas y de significado. Rodríguez (1999) explica que la reducción de datos es "la simplificación, el resumen, la selección de la información para hacerla abarcable y manejable"; su objetivo es categorizar y codificar los datos para "reducir la amplia información que contienen" y facilitar su estudio al investigador. Se utilizan criterios sociales, gramaticales, temáticos, o espacio-temporales como métodos de separación; luego se codifican y clasifican en categorías, para finalmente realizar síntesis y agrupamientos que formen estructuras analizables con mayor objetividad y pertinencia (pp. 205-212).

\section{Resultados}

En esta investigación se hace énfasis en el proceso mediador con las TIC, que juegan un papel de agentes de conocimiento y de temas de interés para estudiantes y maestros; se trata de sacar provecho de los argumentos temáticos y características físicas y morales de los personajes favoritos, para utilizarlos como excusa en procesos de creación artística y literaria. Los maestros pueden tomarlos como base para hacer proyectos transversales que dinamicen la enseñanza y la formación de sus estudiantes en varios niveles y disciplinas a la vez.

Se utilizó un conjunto de estrategias diferenciadas que pueden servir para el desarrollo del proceso creativo, motivar originalidad a partir de fuentes distintas a la literatura, y permitir actividades que complementan las ya utilizadas y probadas ampliamente por la comunidad magisterial para la formación integral de los estudiantes en el área de Lengua Castellana. Tales estrategias son:

a. Relaciones ficcionales: aprovechando las TIC en el aula para divertirse y aprender. Las actividades cumplen con premisas como diálogo sobre los personajes favoritos, programas y películas; entender cualidades y virtudes de los personajes de las ficciones; y desarrollar habilidades con juegos de palabras, y relaciones desde múltiples puntos de encuentro con las ideas y conceptos.

b. Modelos para crear y recrear: cuyo objetivo es realizar una obra artística desde una fuente distinta; por ejemplo, construir una historia a partir de una imagen estática, hacer narración oral o escrita desde los textos audiovisuales, armar historietas y tiras cómicas desde un texto escrito, que también serán fuente para nuevas historias originales que se puedan imaginar desde la serie de ilustraciones. 
c. Mezcla de personajes y acciones para resolución de problemas: donde se permiten interacciones creativas a situaciones extrañas que se le presenten a los niños y niñas. El asunto es motivar creatividad cambiando las historias, personajes o lugares de sus obras ficcionales favoritas, e inventar tramas distintas, o intercambio de roles, para desarrollar nuevas propuestas de originalidad creativa.

La intención general es hacer palpable que todo eso que ven — bueno y malo—en las TIC lo pueden aprovechar como herramienta de aprendizaje del comportamiento humano en general, porque es una manera de mostrar los diversos caracteres y personalidades que pueden ocurrir en las personas a su alrededor. Lo explícito para niñas y niños de grado $2^{\circ}$ puede convertirlos en personas más sociales y más atentas de las necesidades del ser humano y medio ambiente.

Las primeras actividades de tipo oral se dirigen en reconocer sus gustos por algún personaje de internet, televisión o cine que les agrade, y que sean capaces de describirlo a sus compañeros. Se convierte en una exploración para narrar brevemente el sentido de un personaje y su relación con las aventuras que tiene para cumplir sus metas en la historia.

En este primer acercamiento, la descripción se hizo desde la improvisación para elegir qué contar sobre el personaje y el tema, lo cual inició en la mayoría de los grupos un diálogo sobre las historias puntuales de algún capítulo o de una escena de la película. La facilidad de compartir entre ellos propicia interactuar a niñas y niños que conocen bien el personaje, con la pequeña dificultad del desinterés repentino de quien lo desconoce.

A manera de acotación para los docentes, los niños pueden perder de vista el objetivo de este diálogo y tocar diversos temas sin relación, con lo cual se propone que se establezcan tiempos de participación cortos y cambiar de interlocutor principal tan pronto se llegue al lapso indicado.

Se han realizado actividades pictóricas donde representan artísticamente sus personajes favoritos; el proceso evaluativo en su realización, más que el dibujo o lo colorido, consiste en el contexto que se le brinda al personaje. Al principio, alrededor del $60 \%$ de las y los niños puso a su personaje en un lugar determinado, en paisajes o locaciones, con objetos naturales o artificiales, y con sus compañeros de aventuras, antagonistas y herramientas. En el final casi la totalidad de sus obras se presenta en un contexto y con compañía para el personaje.

A continuación se presenta un análisis desde la reducción de datos y categorización de elementos de los cuentos. Las referencias a las narraciones de niñas y niños son literales en su grafía y escritura original. 


\section{Relaciones con la persona humana: cuerpo y espíritu}

Los procesos creativos se empezaron a trabajar desde una actividad propuesta por Gianni Rodari. A partir de una palabra decir otras con relaciones que encuentren en su significado, en el grupo de sistema-parte, desde su experiencia propia con su visión de las palabras base — se propusieron varias_- El objetivo ha sido lograr que los estudiantes puedan pensar en conceptos abstractos y físicos para propiciar el desarrollo de pensamiento divergente, que creativamente busquen relaciones entre objetos y significados, y que se incorpore esta actitud de descubrimiento para potenciar los procesos de lectura y escritura con base en sus gustos y conocimientos.

La originalidad en los niños, desde esta propuesta, Ileva a los más diversos resultados que hacen relación en su mente; por ejemplo, Mateo T., de 8 años (8), conecta desde la palabra "piedra" otros objetos como "roca, pierna, escaleras, dragón, equipaje, escritura, dios, cuadra", logrando 23 palabras en tres minutos de tiempo. Nicole (8), desde "espíritu" logra "Dios, paz, amor, escuchar, ira, amistad, felicidad", hasta 15 palabras. Y también se encuentran otros casos que son de mencionar como Juan David (8), que con sus cuatro relaciones dice muchas cosas que nadie más pensó de "cuerpo": "curbas, maniovras, elastisidad, avilidad".

Algunos otros ejemplos, con la palabra "espíritu", las relaciones fueron para Keyner (8), "fantasma, moustro, demonio, bruja, diablo, duente, extorsismo, chuqui..."; aquí hay una clara influencia de los medios de comunicación en la apropiación de conceptos e ideas en niñas y niños; y se vuelve interesante para padres y maestros poder participar en la explicación de películas y programas de televisión, para que se forme un ámbito de conocimiento formal desde el acercamiento que tienen los niños a los contenidos para adultos en las TIC.

\section{Personajes y sus referentes con la persona humana}

Los personajes ficcionales más recurrentes en las obras fueron Princesita Sofía y Gokú; las niñas siempre se identificaron con una figura femenina y los niños con personaje masculino. Se encontraron también, pero en una escala casi unitaria, personajes de internet y sus videojuegos, como los Angry Birds; del cine, en mayor medida, las sagas de personajes de "Marvel Comics", siendo Capitán América, Thor y Hulk los más nombrados. Por otra parte, personajes conjuntos como los futbolistas de las series televisivas "Sendokay Champions" y "Súper Estrikas".

Se han propuesto actividades para utilizar el tema de la persona humana transversal para grado segundo del Colegio- en la creación de sus cuentos y de sus obras artísticas. Primero, se les pidió que hablaran de las características físicas de sus personajes y surgieron los siguientes resultados: 
Dieron, en promedio por estudiante, 4 elementos distintivos de sus personajes en su físico; las respuestas más frecuentes fueron "flaco/a", "alto/a", "musculoso", y comentarios de la forma del cabello; las siguientes fueron sobre su vestimenta, y sus habilidades — volar, fuerza superior, etc.—; todo esto es, de alguna forma, normal y predecible; pero hubo descripciones espontáneas como la de Zayra (7), "hombre parece niña", hablando de Finn —Finn y Jake-, un joven que oculta su largo cabello rubio bajo un casco o gorro; o Estevan (8) que dice de Gru —Mi villano favorito- que es el hombre que "robó la Luna", como característica física, única y diferenciadora.

Respecto a la espiritualidad y forma de ser de sus personajes, las características son más frecuentes en todos los niños, siendo las frases que hablan de la "ayuda que brindan a las personas" la actitud más dicha por niñas y niños; luego la "bondad", en la calidad de ser buena persona; también "compartir" sus cosas con los demás fue valorado en tercer lugar desde las descripciones. Hubo procesos casi inferenciales sobre el comportamiento de sus personajes, como Sergio (8) que opina que Spiderman "va contra su amor verdadero", en clara referencia a Mary Jane y la relación sentimental de ella con su amigo/archienemigo Harry.

\section{Temas principales de los cuentos}

La mayoría de historias se tratan sobre conflictos entre los protagonistas, los casos más frecuentes son Gokú peleando con algunos de sus enemigos, o Eli Shane, de Bajo Terra, luchando con sus babosas. La Princesita Sofía la mayoría de veces participa en concursos, o busca algún objeto precioso. Dependiendo del personaje elegido pueden estar viajando a algún lugar maravilloso o alejado.

Otros temas diversos que se proponen son expuestos de maneras fantásticas; así Jimena (8) dice "Havia una ves una selva amasonica en el espacio donde vivian muchas personas, un dia vieron que una roca jigante que se dirigía a la luna [...] todos estaba en pánico...". El manejo de la imaginación permite comprender las emociones que se pueden presentar según las situaciones; o inventarse finales extraordinarios como el de Santiago (9) con la brujita Grachi: "provo un hechiso de magia que dice haci: que del viento vengan las oras que se detenga el relog con este hechiso te combiertes en un pobre saaaapooooo y el que estaba al frente se combirtio en sapo".

En cuestión de amores también todo puede ocurrir; Juliana (8) cuenta que la niña con su conejo venían de un sitio muy lejano, conoce al príncipe quien "le dijo que si se queria casar con ella y ella le dijo que si y sedieron un veso en la boca y se enamoraron $[. .$.$] y despues la niña le dijo lo estraño y la princesa se puso triste$ porque no yegada a la casa con el conejo y el principe no le dijo nada Fin". 
Algunos niños y niñas muestran, tal vez, sucesos que les han ocurrido en sus casas; Ana (7) narra: "y el hermano se yamaba luis le gustaba jugar a las escondidas y a la hermana no le gustaba jugar (...) y un dia y van a jugar a las escondidas y un dia a los bebes pero a el no le gustaba jugar a los bebes [...] por que el tenia 10 años y [...] y la niña ya nunca bolbio ajugar a los bebes". En este caso el cuento no tiene ningún personaje ficcional pero es importante ver que los conflictos internos pueden salir a la luz a partir de las oportunidades de narración.

\section{Lugares y tiempos: descripciones del espacio narrativo}

A lo largo de la experiencia con los personajes ficcionales se ha cambiado el tradicional "había una vez", y "érase una vez" por construcciones que tienden a reflejar el contexto situacional y de tiempo del cuento. Se ha hecho énfasis a los niños para que los inicios de sus historias contengan descripciones de dónde ocurren los hechos, y quiénes van a ser los protagonistas de sus cuentos.

Nicole (8) empieza así un relato: "Era un dia soleado, Dog está triste porque su muñeca estaba rota..."; Keyner (8) habla sobre Gumball "es don de un gato donde se Ilama gombal y su hermano que le salieron patas y manos...". Pueden igual proponer el inicio tradicional, pero adicionan un punto de inflexión de una trama, como Ivan (8) que dice: "Érase una vez en un lejano pueblo un niño que sueña ser el mejor vaquero del pueblo que sera el que atrapaba los ladrones...". También describen una situación metafórica como inicio; Juan David (8) comenta: "era un Dia calido y muy caliente era Dia de competencia Dusty se a lista para la carrera...".

\section{Evaluaciones sobre los temas de la persona humana}

Se tuvo en consideración, desde el principio, que al tomar personajes ficcionales se podría llevar a algún tipo de confusión por parte de los niños y niñas sobre su percepción y concepción de cualidades físicas de las personas, y trasladar las de los personajes de caricatura volviéndolas "una realidad" en ellos mismos. Por lo tanto, se realizaron evaluaciones distintas sobre tres conceptos que los niños deberían estar adquiriendo a lo largo del proceso investigativo: salud, desarrollo espiritual y diferencias entre el súper héroe y la persona humana. 
Tabla 1.

¿Cómo sabes que las niñas y los niños tienen buena salud?

\begin{tabular}{|l|l|}
\hline Respuestas basadas en la alimentación & $85 \%$ \\
\hline Alimento más ejercicio & 10 respuestas \\
\hline Sólo alimentos & 8 \\
\hline Alimento más otros conceptos & 4 \\
\hline Ausencia de enfermedades & 2 respuestas \\
\hline Higiene personal & 1 \\
\hline Autonomía de la persona & 1 \\
\hline
\end{tabular}

Fuente: Elaboración propia.

Este diagrama condensa la manera en que los niños consideran en su gran mayoría que el alimento es la base de una buena salud; lo interesante es que el tema de estudio transversal para el grado primero fue la alimentación, en grado segundo es la persona, en tercero será su relación con la escuela, etc., de esta manera se puede apreciar que el énfasis que se da en el curso anterior ha sido comprendido por los niños como la base para una mejor salud.

Ana María (7) da un completo plan nutricional para mantenerse saludable: "... comen fruta comen vegetales y comen muchas vitaminas y comen carne pollo y plátano zanahoria etc., y se alimentan bien". La mayor cantidad de respuestas se acompañaron del concepto de ejercitar el cuerpo, con gimnasia y deportes; Mateo F. (7) expresa "comer muy saludavle acer deporte, aciendo ejersiso se buelbe muy fuerte, mober pesas, divirtiendoce y asiedo mucho ejercicio".

También se preguntó por la calidad de ser buenas personas, de tal manera que se pudieran valorar los conceptos de desarrollo espiritual, motivación de valores y virtudes en ellos, y todo lo que acompaña el proceso interno para la formación de personas que viven en una sociedad. 
Tabla 2.

¿Cómo sabes cuándo niños y niñas son buenas personas?

\begin{tabular}{|l|l|}
\hline Respuestas basadas en ayuda a los demás & $46 \%$ \\
\hline $\begin{array}{l}\text { Ayuda más generosidad } \\
\text { Ayuda más respeto }\end{array}$ & 3 respuestas \\
\hline $\begin{array}{l}\text { Ayuda más otros (trabajo, honradez, } \\
\text { paz, amor, etc.) }\end{array}$ & 2 \\
\hline $\begin{array}{l}\text { Basadas en compartir con sus semejantes } \\
\text { Compartir más dar amistad }\end{array}$ & 7 \\
\hline Compartir más colaboración & $19 \%$ \\
\hline Otras (buen trato, amabilidad, honestidad) & 3 respuestas \\
\hline
\end{tabular}

Fuente: Elaboración propia.

Se puede notar que hay diversas maneras en que las personas se muestran con calidad de buenas para niñas y niños, sin embargo la mayoría se ha decidido por la ayuda que prestan a los demás, y siempre se conjugó con otras cualidades adicionales para complementar.

Ayuda y generosidad son importantes para Nicole (8) que dice: "Cuando los niños colaboran a las personas, y cuando las personas no tienen nada de comer, los niños le dan plata o algo de comer así se ven los niños buenos". Julián (8) integra otro valor a explicación: "cuando ayudan honestamente y cuidan a los viejos, y que son honestos honrando a Dios".

Las otras respuestas, que tratan de diversas acciones y virtudes de las personas, por ejemplo son: Enrique (7) dice: "Pues asiendo caso ser juicioso educándolos también porque estudian y aprenden"; Ana María (7) "(...) ellos pueden nacer con felicidad o tanbien amables o tanbien no pueden nacer amable y hay otros que la mamá los enseña". Aquí, como se ve, influye la educación como medio de transformación en buenas personas que pueden hacer algo para mejorar en sí mismos. 
Para finalizar esta sección de evaluaciones, también se les preguntó por las diferencias entre una persona normal y un superhéroe; las respuestas fueron en su mayoría cortas, y describían más las capacidades físicas que las espirituales. Sin embargo, ninguno concibe la idea que una persona común y corriente se convierta en superhéroe ya que su cuerpo normal no lo hace apto para ello, aunque se pueden parecer los humanos a ellos.

En los niños es importante respetar al ser humano tal como es; la apreciación de Sofía (8) dice "(...) encambio los umanos no tienen poderes pero si tenemos fuersa y un sentimiento que nadie se puede rreir, y tenemos defetos lo mismo que los superhéroes". Aquí se nota que los niños pueden concebir ideas concretas en las cualidades de ambos tipos de personas y personajes.

\section{Tópicos narrativos de los argumentos}

Para este análisis se tomó una sola de las narraciones de niñas y niños de $2^{\circ}$ grado; la que corresponde a una actividad mixta donde primero se dibujaba en una serie tipo tira cómica la situación que vivía el personaje ficcional, y luego se expresaba por escrito a partir de la historia construida y que diera otra vida a la imágenes pintadas con anterioridad.

Esta experiencia desea valorar los contenidos de los argumentos utilizados desde el punto de vista moral del cuento, en búsqueda de expresiones de conflicto entre el bien el y el mal, o la ausencia de referencias claras de ello, y el manejo que se le da a la narración.

Tabla 3. Narraciones morales, el bien y el mal

\begin{tabular}{|l|l|}
\hline Historias de conflictos con base argumental de bien y mal & $33 \%$ \\
\hline Conflictos sin profundidad (no se especifica buenos o malos) & $44 \%$ \\
\hline Narraciones descriptivas de una acción inocua & $22 \%$ \\
\hline
\end{tabular}

Fuente: Elaboración propia.

Los análisis rescatan argumentos referente a lo moral — bien y mal— cuando hay una lucha que se establece entre dos personajes, y que han sido diferenciados por esa calidad de su modo de ser. Los conflictos sin profundidad se establecen en la ausencia del componente de maldad y bondad; es la narración de una lucha entre dos seres que tienen sus cualidades únicamente en la mente del escritor. Se alojaron en la categoría de narraciones descriptivas aquellas donde se busca un objeto de deseo, o simplemente se describe una situación o lugar. 
Sobre este ítem hay que anotar que niñas y niños, desde el principio, casi no expresan cualidades de los personajes, porque consideran que no hace falta para describirlos. El conjunto de aptitudes y actitudes está intrínseco en el personaje ficcional, que ellos y sus compañeros reconocen, y no sintieron necesario escribir todas sus cualidades. A partir de esto, se han tomado muchas acciones para mostrar la importancia del contexto en los personajes de sus cuentos.

Sergio (8): "havia una vez un perro que no tenía poderes, y estaba encerrado en una jaula y el doctor iva a bacunarlo para acerlo malvado y el perro ecapo [...] y se le rompio el frasco encima del perro y el corro mucho"; en esta historia ese líquido lo hizo poderoso, salvó a un niño amigo, atrapó ladrones y se enamoró de una perrita.

Julián (8) narra "había una vez un pequeño hechicero pero pasa una sola cosa que lo habia buelto malo lo habian traicionado por eso solo era himaginario..."; ese hechicero convierte la selva en algodón, se pone bravo con otros magos, y alguno de ellos descubre que si le borra la mente se vuelve bueno otra vez.

Danna (8) escribe "(...) y todos eran amigos y se respetavan y amables y esteroides [asteroides] iban a quitar la luna y el sol el esteroide son malos y malvados y no son respetuosos ni amable y atacaron a la gente buena y los amigos de los malos..."; finalmente los malos ganan en el cuento, porque tiran una bola de fuego que acaba con el "mundo de Bogota".

De nuevo se quiere hacer notar que las historias son creativas e interesantes; albergan una gran cantidad de referencias sobre el bien y el mal, sobre las acciones que realizan los malos en contra de las personas, y cómo los buenos, humanos o animales, tratan de salvar a la gente que no puede hacerlo por sí misma, o que no tienen la capacidad para detectar el peligro que se les avecina.

Para finalizar esta parte del análisis de resultados se dará una pequeña muestra de magníficos fragmentos creativos y originales que los niños empiezan a realizar:

Sara (8): "Un dia por la noche dejaron una ventana abierta y la Ilubia tenía poder y se entro y le dio poder a la mujer...". Es fantástica esta capacidad para asignar un valor emotivo a una situación inicial de un cuento.

Zayra (7): "(...) los niños se pusieron vrabos y tristes botaron todos los jugetes al fuego...". Muestra un sentimiento de impotencia ante la situación, las emociones emergen y se actúa en consecuencia. 
Sofía (8): “(...) y ella se sintió mal con los señores y las señoras". Es el final adecuado para mostrar la transformación que puede sufrir la persona malvada; darse cuenta que su error y sentirlo profundamente.

Juan David (8): "Erase una vez un dia mui soleado y de repente suena un grito". Otro inicio que impacta al lector, donde contrasta bruscamente el ambiente con la situación que genera el conflicto. Maravilloso.

Estos son unos pocos ejemplos de los diversos procesos relacionales que se logran en la mente de niñas y niños, y que por lo general, en la mayoría de colegios del país, no son motivados en las clases tradicionales, que siguen modelos pedagógicos de antaño, que se preocupan por un "transmisionismo" de datos en vez de la generación creativa de estructuras mentales a partir de la originalidad e innovación de niñas y niños.

\section{Conclusiones}

Se reflexiona sobre tres temas principales: la pertinencia de esta investigación; los encuentros con base en los cuentos de los niños y elementos que se pueden adicionar al conjunto de estrategias presentadas y probadas con este proyecto que serían útiles en el aula de clase.

El proyecto "Personajes ficcionales para creación literaria" se ha convertido en una investigación pertinente en el campo de la mediación de los procesos de lectura y escritura en la infancia; sirve en el sentido que pretende como objetivo la producción textual y literaria, mejorando el aprendizaje de la lectura de textos audiovisuales, imágenes y multimediales, y habilita un proceso de oralidad narrativa a partir de sus gustos por películas, programas y series de televisión que les gusta.

Hay un desarrollo multifacético en los niños que toman distintos personajes ficcionales para sus cuentos, y esto nutre de diversidad la apropiación de valores morales, características de conducta, y de acciones diferentes llevadas a las narraciones y obras pictóricas. Esto da muchas posibilidades para centrar las futuras actividades a realizar, porque clarifica lo que sucede realmente en la mente de un niño, y que no corresponde a una respuesta adulta que busca precisión y centrarse al tema particular por el cual se pregunta.

En segundo lugar, los encuentros de la investigación a partir del análisis de resultados una vez propuestas estas estrategias. Como se expresó ampliamente en la sección de Resultados, las propuestas y los productos literarios de los estudiantes se beneficiaron en gran medida con la ganancia paulatina y constante de formas $y$ estructuras literarias que recogen sentimientos, emociones y pensamientos del rico 
universo que llevan los estudiantes desde sus personajes ficcionales favoritos. Se crean nuevas ficciones porque son capaces de reconocer las experiencias de su entorno en comparación con la fantasía animada y dramática que hay en las TIC.

Tampoco se pretende afirmar que el 100\% de los estudiantes ha tenido un cambio radical en su manera de expresión creativa, pero sí es ostensible la evolución de muchos de ellos, y la apropiación de nuevas maneras de comunicación que reflejan una transformación cognitiva y sensorial desde una nueva forma de ver televisión, o de contactarse con las TIC en general, para sacar de allí las ideas que plasman en sus obras literarias.

Por último, pensando en las actividades que se realicen para un proyecto de afianzamiento de esta investigación, o de adicionar actividades y estrategias, se puede llevarlos al mundo de la mímica, la expresión física de emociones, la dramatización improvisada de cuentos, y seguir con la motivación de la originalidad y creatividad desde el aporte de las TIC y de la literatura para combinar acciones entre personajes y situaciones de diversas fuentes. Así se complementan los factores de inteligencias múltiples que pueden tener los niños, y motivar el desarrollo de su parte lingüística a partir de los otros sistemas internos de ellos.

Es difícil concretar un proceso de este estilo en las aulas, pero se puede lograr poco a poco presentando propuestas sencillas a partir de lo aprendido en esta investigación. Entre más explícita y gradual sea la guía de realización de las actividades, o si se proponen en forma de talleres más transversales, la apropiación de un maestro de estas estrategias puede ser más fácil y gratificante. 


\section{Referencias}

Cerrillo, P. (2007). Los nuevos lectores: la formación del lector literario. Biblioteca Virtual Miguel de Cervantes. Recuperado de: http://www.catedravargasllosa.com/obra-visor-din/ los-nuevos-lectores-la-formacin-del-lector-literario-0/html/013fed66-82b2-11 df-acc7002185ce6064_4.html\#I_0_

Dolezel, L. (1999). Estudios de poética y teoría de la ficción. Murcia: U. de Murcia.

Jones, G. (2002). Matando monstruos. Por qué los niños necesitan fantasía, super-héroes y violencia imaginaria. Barcelona: Editorial Ares y Mares.

Pérez, M., y Roa, C. (2010). Herramienta para la vida. Bogotá: SED. Reyes, Y. (2005). La lectura en la primera infancia. Bogotá: CERLAC. Rodari, G. (1983). Gramática de la fantasía. Barcelona: Imprenta Juvenil.

Rodríguez, G. (1999). Metodología de la investigación cualitativa (2ª ed.). Málaga: Ed. Aljibe.

Recibido: 26 de febrero de 2015

Aceptado: 30 de abril de 2015

Como citar: González, J.E. (2015) Personajes ficcionales para creación

literaria. Praxis Pedagógica, 17, 25-45 